Correspondence

K. A. Talukder

kaisar@icddrb.org

Received 25 August 2006

Accepted 14 November 2006

\section{Shiga toxin-producing Escherichia coli isolated from patients with diarrhoea in Bangladesh}

\author{
M. Aminul Islam, ${ }^{1,2,4}$ A. E. Heuvelink, ${ }^{2}$ E. de Boer, ${ }^{2}$ P. D. Sturm, ${ }^{3}$ \\ R. R. Beumer, ${ }^{4}$ M. H. Zwietering, ${ }^{4}$ A. S. G. Faruque,${ }^{1}$ R. Haque, ${ }^{1}$ D. A. Sack ${ }^{1}$ \\ and K. A. Talukder ${ }^{1}$ \\ ${ }^{1}$ International Centre for Diarrhoeal Disease Research, Bangladesh: Centre for Health and \\ Population Research, GPO Box-128, Dhaka-1000, Bangladesh \\ ${ }^{2}$ Food and Consumer Product Safety Authority, Zutphen, The Netherlands \\ ${ }^{3}$ Department of Medical Microbiology, Radboud University Nijmegen Medical Center, Nijmegen, \\ The Netherlands \\ ${ }^{4}$ Laboratory of Food Microbiology, Wageningen University, The Netherlands
}

The prevalence of Shiga toxin-producing Escherichia coli (STEC) and its characteristics were determined among hospitalized patients with diarrhoea and children with diarrhoea in an urban slum community of Dhaka city using sensitive culture and PCR methods. Stool samples were collected from 410 patients with diarrhoea enrolled in the $2 \%$ surveillance system (every 50th patient attending the hospital with diarrhoeal disease is included) at the ICDDR,B hospital and from 160 children of 2-5 years of age with diarrhoea living in an urban slum in Dhaka, between September 2004 and April 2005. Shiga toxin genes (stx) were detected by multiplex PCR in the enrichment broth of nine samples (2.2\%) from hospitalized patients and 11 samples (6.9\%) from the community patients. STEC was isolated from five stool samples with positive PCR results using a colony patch technique. All five isolates were positive in the Vero cell assay and PCR fragments of stx genes were confirmed by sequencing. Two isolates were positive for the $E$. coli attaching-and-effacing (eae) gene and four were positive for the enterohaemolysin ( $\left.h / y_{\mathrm{EHEC}}\right)$ gene and enterohaemolysin production. The five isolates belonged to five different serotypes: O32 : H25, O2 : H45, O76 : H19, ONT : H25 and ONT : H19. It can be concluded that STEC is not a common pathogen in Bangladesh among hospitalized patients with diarrhoea nor among mild cases of diarrhoea in the community.

\section{INTRODUCTION}

Shiga toxin-producing Escherichia coli (STEC) is an important causative agent of haemorrhagic colitis and diarrhoea-associated haemolytic-uraemic syndrome (HUS) with or without neurological complications (Karmali, 1989; Nataro \& Kaper, 1998; Paton \& Paton, 1998a). STEC is a serologically diverse group of foodborne, zoonotic pathogens. Serotype O157:H7 has been the predominant type worldwide (Tarr et al., 2005). However, altogether more than 200 STEC serotypes have been reported and more than 100 have been linked with human infection (Eklund et al., 2001). In some geographic areas, STEC non-O157 is more commonly isolated from persons with diarrhoea or HUS than STEC O157 strains (Pradel et al., 2000).

Although most sporadic cases and outbreaks have been reported from developed countries, human infections

Abbreviation: STEC, Shiga toxin-producing Escherichia coli. associated with STEC strains have also been described in Latin America, India and other developing countries (Kaddu-Mulindw et al., 2001; Leelaporn et al., 2003). In Bangladesh, the predominant group of $E$. coli associated with childhood diarrhoea is enterotoxigenic E. coli, accounting for approximately $20 \%$ of all diarrhoeal cases (Qadri et al., 2005). The burden of STEC-associated diarrhoea in Bangladesh is unknown. In the present study, we investigated the prevalence of STEC among hospitalized patients with diarrhoea as well as among patients with diarrhoea attending the community clinics. The STEC isolates were characterized in detail.

\section{METHODS}

Stool samples. Between September 2004 and April 2005, stool samples were collected from patients with diarrhoea enrolled in an ongoing active surveillance system at the Dhaka treatment centre operated by the International Centre for Diarrhoeal Disease Research, Bangladesh (ICDDR,B). In this surveillance system, every 
50th patient attending the hospital with diarrhoeal disease is included. A detailed history of the patients is obtained, including information on the age, sex and clinical presentation. Stool samples were collected in sterile McCartney bottles and transported to the laboratory within $1 \mathrm{~h}$.

In the same period, stool samples were collected from children having complaints of diarrhoea attending the Centre's community clinic at Mirpur, an urban slum in Dhaka. The inhabitants of Mirpur are of Bihari ethnic origin and settled there after the separation of Bangladesh from Pakistan in 1971. The area is densely populated and has poor sanitary and hygiene conditions. Clinical information was collected by health care workers who visited the children and their parents every other day. Stool samples were kept on ice, and transported to the laboratory for processing within $2-4 \mathrm{~h}$ after collection.

Isolation procedure for STEC 0157. A loopful of stool sample was inoculated into $3 \mathrm{ml}$ modified tryptone soy broth (Oxoid) and incubated overnight at $37^{\circ} \mathrm{C}$. Immunomagnetic separation using Dynabeads anti-E. coli O157 (Dynal) was performed with $1 \mathrm{ml}$ broth culture, following the manufacturer's instructions. The immunoconcentrated samples were inoculated onto two selective isolation media: sorbitol-MacConkey agar (Oxoid) supplemented with cefixime $\left(0.05 \mathrm{mg} \mathrm{l}^{-1}\right)$ and tellurite $\left(2.5 \mathrm{mg} \mathrm{l}^{-1}\right)$ (Oxoid) (CT-SMAC); and CHROMagar O157 (ITK Diagnostics BV) with cefixime $\left(0.025 \mathrm{mg} \mathrm{l}^{-1}\right)$ and tellurite $\left(1.25 \mathrm{mg} \mathrm{l}^{-1}\right)(1 / 2 \mathrm{CT}-\mathrm{CHROM})$. The agar plates were incubated for $18-24 \mathrm{~h}$ at $37^{\circ} \mathrm{C}$. Typical colonies (colourless colonies on CT-SMAC and mauve on $1 / 2 \mathrm{CT}$ CHROMagar), up to 12 per plate, were selected and streaked onto tryptone soy agar (TSA) plates. The colonies on TSA plates were tested for agglutination with an E. coli O157 latex test kit (Murex) and a PCR for the $r f b \mathrm{E}_{\mathrm{O} 157}$ gene, which is specific for E. coli $\mathrm{O} 157$ (Table 1).

Detection and isolation of STEC non-0157 types. The overnight incubated enrichment broth was also examined by PCR using st $x_{1}$ and $s t x_{2}$ primers (Table 1). DNA was extracted from $1 \mathrm{ml}$ broth culture by thermal cell lysis using Chelex-100 resin (Bio-Rad) (Malorny et al., 2003) and $5 \mu$ of the DNA extract was used in the PCR. Touchdown multiplex PCR for $s t x_{1}$ and $s t x_{2}$ was carried out in a PTC-200 peltier thermal cycler (Bio-Rad). After initial incubation at $94{ }^{\circ} \mathrm{C}$ for $5 \mathrm{~min}$, a 40 -cycle amplification protocol was implemented as follows: $94{ }^{\circ} \mathrm{C}$ for $30 \mathrm{~s}, 64^{\circ} \mathrm{C}$ for $30 \mathrm{~s}$ and $72{ }^{\circ} \mathrm{C}$ for $60 \mathrm{~s}$ for two cycles followed by eight cycles with decreasing annealing temperatures of $2{ }^{\circ} \mathrm{C}$ in every two cycles. When the annealing temperature of $54^{\circ} \mathrm{C}$ was reached at cycle 10 , the PCR was continued with these cycling parameters followed by a final extension of $10 \mathrm{~min}$ at $72^{\circ} \mathrm{C}$. All PCR fragments for $s t x_{1}$ and $s t x_{2}$ genes were subjected to sequencing. After electrophoresis, bands of PCR products were extracted and purified using the PCR Product Purification kit (Roche). Subsequently, a cycle-sequence reaction was performed using a kit (BigDye Terminator v3.1 cycle-sequencing kit; Applied Biosystems) according to the manufacturer's protocol. Purified PCR products were sequenced on an automated sequencer (ABI Prism 3100-Avant Genetic Analyser; Applied Biosystems). The chromatogram sequencing files were inspected using Chromas 2.23, and contigs were prepared using SeqMan II (DNASTAR). Nucleotide sequence similarity searches were performed using the National Center for Biotechnology Information (NCBI) Basic Local Alignment Search Tool (BLAST) server on the GenBank database, release 138.0.

Broth cultures that yielded positive PCR results for $s t x_{1}$ and $s t x_{2}$ or both were streaked onto tryptone bile X-glucuronide (TBX) agar (Oxoid) supplemented with cefixime $\left(20 \mu \mathrm{g} \mathrm{l}^{-1}\right)$, cefsulodin $\left(3 \mathrm{mg} \mathrm{l}^{-1}\right)$ and vancomycin $\left(30 \mathrm{mg} \mathrm{l}^{-1}\right)$ (CCV-TBX). Single colonies including different morphological types were transferred from the CCV-TBX and plated onto Luria agar (Difco) to create a grid pattern of 96 colonies $(12 \times 8)$. The plates were incubated overnight at $37^{\circ} \mathrm{C}$. The isolates were subjected to PCR for the detection of $s t x_{1}$ and $s t x_{2}$ as described above. The number of PCR reactions was reduced to 20 by pooling the colonies per row and per column in $500 \mu \mathrm{l}$ sterile distilled water. DNA was extracted by boiling the suspensions for $10 \mathrm{~min}$ and $5 \mu \mathrm{l}$ of the supernatant was used in the PCR. The isolates with positive PCR results were identified as E. coli by an API 20E test (bioMérieux).

Characterization of STEC isolates. All isolates were sent to the National Institute of Public Health and the Environment (RIVM) in Bilthoven, the Netherlands, for $\mathrm{O}$ and $\mathrm{H}$ typing. Production of Shiga toxin was determined by Vero cell culture assay (Karmali et al., 1985a). The isolates were tested by PCR for the presence of the $E$. coli attaching-and-effacing (eae) and the enterohaemolysin ( $h l y_{\mathrm{EHEC}}$ ) genes (Heuvelink et al., 1995; Wieler et al., 1996). The oligonucleotide primers used for PCR are listed in Table 1. Enterohaemolytic activity was examined by streaking the isolates onto tryptone soy agar supplemented with $10 \mathrm{mM} \mathrm{CaCl}$ and $5 \%$ defibrinated sheep blood cells washed three times in PBS ( $\mathrm{pH} 7.2$ ), as described previously (Beutin et al., 1989). The plates were observed for haemolysis after $4 \mathrm{~h}$ ( $\alpha$-haemolysis) and after overnight incubation in ambient air at $37^{\circ} \mathrm{C}$ (enterohaemolysis or nonhaemolysis).

Isolation of other enteric pathogens. All samples from hospitalized patients were examined for other enteric pathogens in addition to STEC, including Vibrio cholerae, Salmonella spp., Shigella spp. and Aeromonas spp., using standard microbiology procedures (World Health Organization, 1987).

Statistical analysis. Data were entered and statistical analyses were performed using SPSS and Epi-Info. The significance of difference in

Table 1. PCR primers used in this study

\begin{tabular}{|c|c|c|c|c|}
\hline Primer & Sequence $\left(5^{\prime}-3^{\prime}\right)$ & Target & PCR product (bp) & Reference \\
\hline$s t x_{1} \mathrm{R}$ & TGT TGC AGG GAT CAG TCG TAC GGG GAT GC & & & \\
\hline$s t x_{2} \mathrm{R}$ & GCA GAA CTG CTC TGG ATG CAT CTC TGG TC & & & \\
\hline$e a e \mathrm{~F}$ & TGCGGCACAACAGGCGGCGA & eae & 629 & Heuvelink et al. (1995) \\
\hline$e a e \mathrm{R}$ & CGGTCGCCGCACCAGGATTC & & & \\
\hline$h l y_{\mathrm{EHEC}} \mathrm{R}$ & CCTGCTCCAGAATAAACCACA & & & \\
\hline$r f b \mathrm{O} 157 \mathrm{~F}$ & CGGACATCCATGTGATATGG & $r f b \mathrm{E}_{\mathrm{O} 157}$ & 259 & Paton \& Paton (1998b) \\
\hline$r f b O 157 \mathrm{R}$ & TTGCCTATGTACAGCTAATCC & & & \\
\hline
\end{tabular}


proportions was evaluated by the $\chi^{2}$ test, and Fisher's exact test was applied when appropriate. $P<0.05$ was considered statistically significant.

\section{RESULTS AND DISCUSSION}

Over the years, STEC has been found to be associated with all forms of diarrhoeal infection ranging from watery to severe bloody diarrhoea. Bangladesh is an endemic zone for diarrhoeal diseases: every year, more than $5 \%$ of deaths of children below 5 years of age are attributed to diarrhoea (Arifeen et al., 2005). In Bangladesh, no STEC infection among the patients with diarrhoea has been reported (Albert et al., 1995). The reasons might be (1) the lack of proper surveillance for STEC, (2) STEC is not present or (3) STEC is present but relatively few infections occur due to acquired immunity in the population. A study on the prevalence of STEC in neighbouring Calcutta, India, showed a very low prevalence of STEC among hospitalized patients with diarrhoea $(1.4 \%$ and $0.6 \%$ of bloody and watery stool samples, respectively) (Khan et al., 2002). The present study was aimed at measuring the burden or occurrence of STEC infection among the patients with diarrhoea in the hospital and in the community using sensitive culture and PCR methods.

\section{Prevalence of STEC}

Of 410 stool samples collected from hospitalized patients, nine $(2.2 \%)$ were positive by PCR: four for $s t x_{2}$ only, three for $s t x_{1}$ only and two for both $s t x_{1}$ and $s t x_{2}$ (Table 2). No statistically significant correlation between the age of patients and the presence of stx genes was observed. All stx positive patients were clinically diagnosed as having uncomplicated diarrhoea. All patients had watery diarrhoea and mucus was present in the stool samples. Vomiting was recorded for seven patients $(78 \%)$. Interestingly, seven of the nine patients were primarily diagnosed with a $V$. cholerae $\mathrm{O} 1$ infection (Table 2). The relative frequency of other enteric pathogens detected in the hospital samples is shown

Table 2. Presence of stx genes in stool samples, clinical manifestation and stool characteristics of patients positive for stx genes

stx, Shiga toxin; F, female; M, male; Metro, metronidazole; UID, unidentified; Cotri, cotrimoxazole; Ery, erythromycin; UCD, uncomplicated diarrhoea; ND, not done.

\begin{tabular}{|c|c|c|c|c|c|c|c|c|c|c|c|c|c|c|}
\hline \multirow[t]{2}{*}{$\begin{array}{l}\text { Patient } \\
\text { code }\end{array}$} & \multicolumn{2}{|c|}{$\begin{array}{c}\text { Presence of } \\
\text { stx genes }\end{array}$} & \multicolumn{8}{|c|}{ Patient history } & \multicolumn{4}{|c|}{ Stool characteristics } \\
\hline & $s t x_{1}$ & $s t x_{2}$ & $\begin{array}{c}\text { Age } \\
\text { (years) }\end{array}$ & Sex & Fever & Vomiting & $\begin{array}{c}\text { Abdo- } \\
\text { minal } \\
\text { pain }\end{array}$ & $\begin{array}{l}\text { Convul- } \\
\text { sion }\end{array}$ & $\begin{array}{l}\text { Chemo- } \\
\text { therapy } \\
\text { before } \\
\text { arrival }\end{array}$ & Diagnosis & Watery & Bloody & Mucus & $\begin{array}{c}\text { Presence of } \\
\text { other } \\
\text { pathogen } \\
\text { in stool }\end{array}$ \\
\hline \multicolumn{15}{|c|}{ Hospitalized patients } \\
\hline Am 3 & + & - & 70 & $\mathrm{~F}$ & - & $<10$ times & - & - & Metro & UCD & + & - & ++ & None \\
\hline Am 35 & - & + & 7 & M & - & $<10$ times & - & - & None & UCD & + & - & + & V. cholerae $\mathrm{O} 1$ \\
\hline Am 84 & + & + & 22 & $\mathrm{~F}$ & - & $>10$ times & + & - & Metro & UCD & + & - & + & V. cholerae $\mathrm{O} 1$ \\
\hline Am 107 & + & + & 35 & M & - & $<10$ times & - & - & Metro & UCD & + & - & ++ & V. cholerae $\mathrm{O} 1$ \\
\hline Am 113 & - & + & 25 & $\mathrm{~F}$ & - & $<10$ times & - & - & UID & UCD & + & - & + & None \\
\hline Am 167 & - & + & 2 & $\mathrm{~F}$ & - & - & + & - & UID & $\mathrm{UCD}$ & + & - & + & V. cholerae $\mathrm{O} 1$ \\
\hline Am 181 & + & - & 6 & $\mathrm{~F}$ & + & $<10$ times & + & - & UID & UCD & + & - & ++ & V. cholerae $\mathrm{O} 1$ \\
\hline Am 281 & - & + & 18 & $\mathrm{~F}$ & - & - & + & - & None & UCD & + & - & + & V. cholerae $\mathrm{O} 1$ \\
\hline Am 403 & + & - & 18 & $\mathrm{~F}$ & - & $>10$ times & - & - & None & UCD & + & - & + & V. cholerae $\mathrm{O} 1$ \\
\hline \multicolumn{15}{|c|}{ Community patients } \\
\hline AI 1 & + & + & 10 & $\mathrm{~F}$ & + & - & + & - & Cotri & UCD & + & - & - & $\mathrm{ND}$ \\
\hline AI 3 & + & + & 7 & $\mathrm{M}$ & - & - & + & - & None & UCD & + & - & - & $\mathrm{ND}$ \\
\hline AI 9 & + & - & 10 & $\mathrm{M}$ & - & - & + & - & Ery & UCD & + & - & - & ND \\
\hline AI 11 & + & - & 10 & $\mathrm{~F}$ & - & - & + & - & None & UCD & + & - & - & $\mathrm{ND}$ \\
\hline AI 25 & + & - & 11 & $\mathrm{~F}$ & - & - & - & - & None & UCD & + & - & + & $\mathrm{ND}$ \\
\hline AI 48 & + & + & 8 & $\mathrm{~F}$ & - & - & - & - & None & UCD & + & - & - & $\mathrm{ND}$ \\
\hline AI 101 & - & + & 8 & $\mathrm{~F}$ & + & - & + & - & None & UCD & + & - & - & $\mathrm{ND}$ \\
\hline AI 103 & - & + & 8 & $\mathrm{~F}$ & + & - & - & - & None & UCD & + & - & - & $\mathrm{ND}$ \\
\hline AI 130 & + & - & 10 & $\mathrm{M}$ & + & - & + & - & None & UCD & + & - & - & $\mathrm{ND}$ \\
\hline AI 132 & - & + & 11 & $\mathrm{M}$ & - & - & - & - & None & UCD & + & - & - & $\mathrm{ND}$ \\
\hline AI 160 & + & - & 10 & $\mathrm{M}$ & - & - & + & - & None & UCD & + & - & - & ND \\
\hline
\end{tabular}


in Table 3. Of 160 samples collected from the community patients with diarrhoea, $11(6.9 \%)$ were found to be positive: five for $s t x_{1}$, three for $s t x_{2}$ and three for both $s t x_{1}$ and $s t x_{2}$ (Table 2). All patients had mild diarrhoea and were diagnosed as having uncomplicated diarrhoea. STEC could be isolated from two $(22 \%)$ among nine PCR positive samples from the hospitalized patients and three $(27 \%)$ of 11 PCR positive samples from community patients. The prevalence of STEC in hospitalized patients with diarrhoea was very low $(0.5 \%)$, and was somewhat higher among the community patients with diarrhoea $(1.9 \%)$.

Failure to isolate the STEC non-O157 from PCR positive stool samples is still a common problem encountered by researchers around the world (Blanco et al., 2004). According to previous studies, the non-isolation of viable STEC from PCR-positive samples might be due to the presence of very low numbers of bacteria (Khan et al., 2002), the presence of free stx phages in the sample (Karmali et al., 1985b) and loss of stx genes upon subcultivation of strains (Karch et al., 1992). In routine diagnostics, there is no definitive biochemical characteristic, such as sorbitol fermentation in the case of serogroup O157, which can identify STEC irrespective of serotypes from the commensal flora. Therefore, selection of suitable culture media for isolation of STEC non-O157 serogroups is always difficult. In this study, we used TBX agar; this medium allows basic differentiation of E. coli colonies but does not discriminate between STEC and non-STEC. In order to make it more selective we supplemented TBX agar with cefixime $\left(20 \mu \mathrm{g} \mathrm{l}^{-1}\right)$, cefsulodin $\left(3 \mathrm{mg} \mathrm{l}^{-1}\right)$ and vancomycin $\left(30 \mathrm{mg} \mathrm{l}^{-1}\right)$. Antibiotics at these concentrations were used previously with blood agar in order to isolate STEC nonO157 serogroups (Lehmacher et al., 1998). These antibiotic supplements suppress the growth of Gram-positive bacteria, Proteus spp. and Pseudomonas spp., and other E. coli.

Table 3. Prevalence of other bacterial enteropathogens in stool samples from hospitalized patients examined for Shiga toxin-producing $E$. coli

\begin{tabular}{|lc|}
\hline Enteropathogen & Prevalence (\%) \\
\hline Vibrio cholerae O1 El Tor Inaba & 19.0 \\
O1 El Tor Ogawa & 18.0 \\
Shigella flexneri & 2.2 \\
Shigella boydii & 0.7 \\
Shigella dysenteriae & 0.2 \\
Salmonella Typhi & 0.2 \\
Salmonella paratyphi B & 0.2 \\
Salmonella Group C1 & 0.7 \\
Salmonella Group D & 0.2 \\
Salmonella Group C2 & 0.2 \\
STEC O157 & 0.0 \\
STEC non-O157 & 0.5 \\
\end{tabular}

\section{Characterization of STEC isolates}

No STEC O157 was isolated from patients in this study. The serotypes of STEC isolates were different: O32:H25, $\mathrm{O} 2: \mathrm{H} 45, \mathrm{O} 76: \mathrm{H} 19$, ONT:H25, ONT:H19. The characteristics of the O76:H19 isolate in the present study were similar to those described previously (Stephan \& Untermann, 1999) for O76:H19 isolates from asymptomatic human carriers, except for the $s t x_{2}$ gene, which was additionally present in our isolate. STEC ONT:H25 was previously isolated from healthy cattle in Canada with a higher prevalence (22.5\%) compared to the prevalence of $E$. coli O157: H7 (15\%). The virulence properties of our isolate and the isolates from Canada were similar except for the type of stx gene. In contrast to the isolate in the study, which was positive for the $s t x_{1}$, all isolates from Canada were positive for stx $_{2}$ (Sheng et al., 2005). One isolate from the hospitalized patient was of serotype O32:H25. This serotype has not previously been described as being associated with STEC infection in humans or isolated from animals. The other two serotypes in the current study, $\mathrm{O} 2: \mathrm{H} 45$ and ONT:H19, were previously isolated from cattle in Hong Kong (Leung et al., 2003) and India (Pal et al., 1999), respectively.

All five isolates were positive in the Vero cell cytotoxicity test. One from a hospitalized patient and one from a community patient were positive for the eae gene (Table 4). All three isolates from the community patients and one isolate from the hospitalized patients were positive for the $h l y_{\text {EHEC }}$ gene (Table 4). It has been suggested in a previous study that there is an association among the locus of enterocyte effacement (i.e. the location of the eae gene), the enterohaemorrhagic E. coli haemolysin plasmid, and the haemolysin itself of STEC non-O157 isolates (Boerling et al., 1998). E. coli possessing the eae gene were statistically more likely to be enterohaemolytic than E. coli that did not carry this gene (Eklund et al., 2001). STEC having both the eae

Table 4. Shiga toxin-producing $E$. coli isolated from patients with diarrhoea in Bangladesh

\begin{tabular}{|c|c|c|c|c|}
\hline $\begin{array}{l}\text { No. of } \\
\text { strain }\end{array}$ & Source ${ }^{\star}$ & Serotype & PCR result $\dagger$ & Ehly $\neq$ \\
\hline Am 181 & A & $\mathrm{O} 32: \mathrm{H} 25$ & stx $x_{1}+$, eae,$- h l_{\mathrm{EHEC}^{-}}$ & - \\
\hline Am 281 & A & $\mathrm{O} 2: \mathrm{H} 45$ & $s t x_{2}+$, eae,$+ h l y_{\mathrm{EHEC}}+$ & + \\
\hline AI 3 & B & O76:H19 & $s t x_{1,2}+, e a e^{-}, h l y_{\mathrm{EHEC}}+$ & + \\
\hline AI 130 & B & ONT: H25 & $s t x_{1}+, e a e+, h l y_{\mathrm{EHEC}}+$ & + \\
\hline AI 132 & B & ONT: H19 & $s t x_{2}+, e a e^{-}, h l y_{\mathrm{EHEC}}+$ & + \\
\hline
\end{tabular}

*Samples were collected from two different groups of patients with diarrhoea: A, hospitalized patients; B, community patients.

$\dagger$ Carriage of $s t x_{1}$ or $s t x_{2}$ or eae or $h l_{\mathrm{EHEC}}$ gene. +, Positive; -, negative.

‡Ehly, Enterohaemolysin production: +, enterohaemolysin positive; - , no haemolysis or $\alpha$-haemolysis. 
gene and haemolytic properties ( $h l y_{\mathrm{EHEC}}$ gene) is more virulent and causes more human infection than strains carrying only the stx genes (Eklund et al., 2001; Oswald et al., 2000; Schmidt et al., 1995). However, we did not find a more severe clinical presentation in those patients from whom STEC was isolated.

Although STEC has been isolated sporadically from different regions of developing countries, it was never implicated as a major causative agent of diarrhoea. In a previous study in Bangladesh, a total of 452 children with diarrhoea and 602 matched control children without diarrhoea were investigated for the presence of diarrhoeagenic E. coli (Albert et al., 1995). In children (up to 5 years of age) with diarrhoea, enteropathogenic E. coli (EPEC) was the most prevalent $(15.5 \%)$, followed by enterotoxigenic $E$. coli $(12 \%)$, enteroaggregative E. coli $(9.5 \%)$ and diffuse adherent E. coli (8.2\%). Enterohaemorrhagic E. coli possessing a stx gene was not detected in any of the children with diarrhoea but was detected in five children without diarrhoea. No further characterization of these five isolates was performed. STEC-identified diarrhoeal cases in developing countries are often infected with other pathogens as well; for example, in India, $58 \%$ of the STEC positive patients were co-infected with other enteric pathogens (Khan et al., 2002). This trend was also observed in the current study; seven of the nine PCR positive samples from hospitalized patients were also positive for $V$. cholerae. In fact, $V$. cholerae was the most common pathogen isolated from the hospitalized patients included in this study, which accounted for $37 \%$ of samples (Table 3). Therefore, the specific role of STEC in causing diarrhoeal illness in this area is difficult to estimate. The reasons for the low prevalence of STEC-associated diarrhoea among hospitalized and community patients are still not clear. However, protective immunity against STEC could be an explanation, and was addressed by most of the studies done in developing countries (Gianantonio et al., 1964; Lopez et al., 1989; Navarro et al., 2003; Seriwatana et al., 1988). The low prevalence of STEC in Calcutta and possibly other places in India was explained by the fact that Indians acquire protective antibodies at an early age or their cooking practices effectively eliminate STEC (Khan et al., 2002). According to previous studies, this immunity can be $\mathrm{O}$ group-specific or cross-reactive (mucosal) and is normally acquired during infancy (Lopez et al., 1989; Navarro et al., 2003). This could be associated with the repeated antigenic stimulation in a contaminated environment where diarrhoeal diseases are considered endemic (Navarro et al., 2003). It has also been suggested (Beutin et al., 1998) that EPEC infections in early childhood confer cross-reacting protective immunity against STEC types that share common antigens (such as LPS and intimin) with classical EPEC strains. However, a detailed study of the immune status of patients with diarrhoea as well as healthy controls in areas where enteric pathogens are considered to be endemic should be carried out in order to explain these phenomena.

\section{ACKNOWLEDGEMENTS}

This research was funded by the ICDDR,B: Centre for Health and Population Research and by the Netherlands Foundation for the Advancement of Tropical Research (NWO-WOTRO) grant (award number WB 93-415). ICDDR,B acknowledges with gratitude the commitment of the Netherlands Foundation for the Advancement of Tropical Research (NWO-WOTRO) grant to the Centre's research efforts. ICDDR,B also gratefully acknowledges these donors who provide unrestricted support to the Centre's research efforts: Australian International Development Agency (AusAID), Government of Bangladesh, Canadian International Development Agency (CIDA), The Kingdom of Saudi Arabia (KSA), Government of the Netherlands, Government of Sri Lanka, Swedish International Development Cooperative Agency (SIDA), Swiss Development Cooperation (SDC) and Department for International Development, UK (DFID).

\section{REFERENCES}

Albert, M. J., Faruque, S. M., Faruque, A. S., Neogi, P. K., Ansaruzzaman, M., Bhuiyan, N. A., Alam, K. \& Akbar, M. S. (1995). Controlled study of Escherichia coli diarrhoeal infections in Bangladeshi children. J Clin Microbiol 33, 973-977.

Arifeen, S. E., Akhter, T., Chowdhury, H. R., Rahman, K. M. \& Chowdhury, E. K. (2005). Causes of death in children under five years of age. In National Institute of Population Research and Training, pp. 125-133. Bangladesh Demographic and Health Survey 2004. Dhaka, Bangladesh and Calverton, MD: National Institute of Population Research and Training (NIPORT), Mitra and Associates, and ORC Macro.

Beutin, L., Montenegro, M. A., Orskov, I., Orskov, F., Prada, J., Zimmermann, S. \& Stephan, R. (1989). Close association of verotoxin (Shiga-like toxin) production with enterohemolysin production in strains of Escherichia coli. J Clin Microbiol 27, 2559-2564.

Beutin, L., Zimmermann, S. \& Gleier, K. (1998). Human infections with Shiga toxin-producing Escherichia coli other than serogroup O157 in Germany. Emerg Infect Dis 4, 635-639.

Blanco, J. E., Blanco, M., Alonso, M. P., Mora, A., Dahbi, G., Coira, M. A. \& Blanco, J. (2004). Serotypes, virulence genes, and intimin types of Shiga toxin (verotoxin)-producing Escherichia coli isolates from human patients: prevalence in Lugo, Spain, from 1992 through 1999. J Clin Microbiol 42, 311-319.

Boerling, P., Chen, S., Colbourne, J. K., Johnson, R., De Grandis, S. \& Gyles, C. L. (1998). Evolution of enterohemorrhagic Escherichia coli hemolysin plasmids and the locus for enterocyte effacement in Shiga toxin-producing E. coli. Infect Immun 66, 2553-2561.

Eklund, M., Scheutz, F. \& Siitonen, A. (2001). Clinical isolates of non-O157 Shiga toxin-producing Escherichia coli: serotypes, virulence characteristics, and molecular profiles of strains of the same serotype. J Clin Microbiol 39, 2829-2834.

Gianantonio, C., Vitacco, M., Mendilaharzu, F., Rutty, A. \& Mendilaharzu, J. (1964). The hemolytic-uremic syndrome. J Pediatr 64, 478-491.

Heuvelink, A. E., de Boer, E. \& Wernars, K. (1994). Detection of Escherichia coli $\mathrm{O} 157$ : $\mathrm{H} 7$ in raw beef by polymerase chain reaction. De Ware Chemicus 24, 25-43 (in Dutch).

Heuvelink, A. E., van de Kar, N. C., Meis, J. F., Monnens, L. A. \& Melchers, W. J. (1995). Characterization of verocytotoxin-producing Escherichia coli O157 isolates from patients with haemolytic uraemic syndrome in Western Europe. Epidemiol Infect 115, 1-14.

Kaddu-Mulindw, D. H., Aisu, T., Gleier, K., Zimmermann, S. \& Beutin, L. (2001). Occurrence of Shiga toxin-producing Escherichia 
coli in fecal samples from children with diarrhoea and from healthy zebu cattle in Uganda. Int J Food Microbiol 66, 95-101.

Karch, H., Meyer, T., Rüssmann, H. \& Heesemann, J. (1992). Frequent loss of Shiga-like toxin genes in clinical isolates of Escherichia coli upon subcultivation. Infect Immun 60, 3464-3467.

Karmali, M. A. (1989). Infection by verotoxin-producing Escherichia coli. Clin Microbiol Rev 2, 15-38.

Karmali, M. A., Petric, M., Lim, C., Fleming, P. C., Arbus, G. S. \& Lior, H. (1985a). The association between idiopathic hemolytic uremic syndrome and infection by verotoxin-producing Escherichia coli. J Infect Dis 151, 775-782.

Karmali, M. A., Petric, M., Lim, C., Cheung, R. \& Arbus, G. S. (1985b). Sensitive method for detecting low numbers of verotoxinproducing Escherichia coli in mixed cultures by use of colony sweeps and polymyxin extraction of verotoxin. J Clin Microbiol 22, 614-619.

Khan, A., Yamasaki, S., Sato, T., Ramamurthy, T., Pal, A., Datta, S., Chowdhury, N. R., Das, S. C., Sikdar, A. \& other authors (2002). Prevalence and genetic profiling of virulence determinants of nonO157 Shiga toxin-producing Escherichia coli isolated from cattle, beef, and humans, Calcutta, India. Emerg Infect Dis 8, 54-62.

Leelaporn, A., Phengmak, M., Eampoklap, B., Manatsathit, S., Tritilanunt, S., Siritantikorn, S., Nagayama, K., lida, T., Niyasom, C. \& Komolpit, P. (2003). Shiga toxin- and enterotoxin-producing Escherichia coli isolated from subjects with bloody and nonbloody diarrhoea in Bangkok, Thailand. Diagn Microbiol Infect Dis 46, 173-180.

Lehmacher, A., Meier, H., Aleksic, S. \& Bockemuhl, J. (1998). Detection of hemolysin variants of Shiga toxin-producing Escherichia coli by PCR and culture on vancomycin-cefixime-cefsulodin blood agar. Appl Environ Microbiol 64, 2449-2453.

Leung, P. H., Peiris, J. S., Ng, W. W., Robins-Browne, R. M., Bettelheim, K. A. \& Yam, W. C. (2003). A newly discovered verotoxin variant, VT2 $g$, produced by bovine verocytotoxigenic Escherichia coli. Appl Environ Microbiol 69, 7549-7553.

Lopez, E. L., Diaz, M., Grinstein, S., Devoto, S., Mendilaharzu, F., Murray, B. E., Ashkenazi, S., Rubeglio, E., Woloj, M. \& other authors (1989). Hemolytic uremic syndrome and diarrhoea in Argentine children: the role of Shiga-like toxins. J Infect Dis 160, 469-475.

Malorny, B., Hoorfar, J., Hugas, M., Heuvelink, A., Fach, P., Ellerbroek, L., Bunge, C., Dorn, C. \& Helmuth, R. (2003). Interlaboratory diagnostic accuracy of Salmonella specific PCRbased method. Int J Food Microbiol 89, 241-249.

Nataro, J. P. \& Kaper, J. B. (1998). Diarrhoeagenic Escherichia coli. Clin Microbiol Rev 11, 142-201.

Navarro, A., Eslava, C., Hernandez, U., Navarro-Henze, J. L., Aviles, M., Garcia-de la Torre, G. \& Cravioto, A. (2003). Antibody responses to Escherichia coli $\mathrm{O} 157$ and other lipopolysaccharides in healthy children and adults. Clin Diagn Lab Immunol 10, 797-801.

Oswald, E., Schmidt, H., Morabito, S., Karch, H., Marches, O. \& Caprioli, A. (2000). Typing of intimin genes in human and animal enterohemorrhagic and enteropathogenic Escherichia coli: characterization of a new intimin variant. Infect Immun 68, 64-71.

Pal, A., Ghosh, S., Ramamurthy, T., Yamasaki, S., Tsukamoto, T., Bhattacharya, S. K., Nair, G. B. \& Takeda, Y. (1999). Shiga toxinproducing Escherichia coli from healthy cattle in a semi-urban community in Calcutta, India. Indian J Med Res 110, 83-85.

Paton, J. C. \& Paton, A. W. (1998a). Pathogenesis and diagnosis of Shiga toxin-producing Escherichia coli infections. Clin Microbiol Rev 11, 450-479.

Paton, J. C. \& Paton, A. W. (1998b). Detection and characterization of Shiga toxigenic Escherichia coli by using multiplex PCR assays for stx $x_{1}$ st $x_{2}$, eaeA, enterohemorrhagic E. coli hlyA, $r f b_{\mathrm{O} 111}$, and $r f b_{\mathrm{O} 157}$. J Clin Microbiol 36, 598-602.

Pradel, N., Livrelli, V., De Champs, C., Palcox, J. B., Reynaud, A., Scheutz, F., Sirot, J., Joly, B. \& Forestier, C. (2000). Prevalence and characterization of Shiga toxin-producing Escherichia coli isolated from cattle, food, and children during a one-year prospective study in France. J Clin Microbiol 38, 1023-1031.

Qadri, F., Svennerholm, A. M., Faruque, A. S. \& Sack, R. B. (2005). Enterotoxigenic Escherichia coli in developing countries: epidemiology, microbiology, clinical features, treatment and prevention. Clin Microbiol Rev 18, 465-483.

Schmidt, H., Beutin, L. \& Karch, H. (1995). Molecular analysis of the plasmid-encoded hemolysin of Escherichia coli O157:H7 strain EDL 933. Infect Immun 63, 1055-1061.

Seriwatana, J., Brown, J. E., Echeverria, P., Taylor, D. N., Suthienkul, O. \& Newland, J. (1988). DNA probes to identify Shiga-like toxin I- and II-producing enteric bacterial pathogens isolated from patients with diarrhoea in Thailand. J Clin Microbiol 26, 1614-1615. Sheng, H., Davis, M. A., Knecht, H. J., Hancock, D. D., Van Donkersgoed, J. \& Hovde, C. J. (2005). Characterization of a Shiga toxin-, intimin-, and enterotoxin hemolysin-producing Escherichia coli ONT:H25 strain commonly isolated from healthy cattle. J Clin Microbiol 43, 3213-3220.

Stephan, R. \& Untermann, F. (1999). Virulence factors and phenotypical traits of verotoxin-producing Escherichia coli strains isolated from asymptomatic human carriers. J Clin Microbiol 37, 1570-1572.

Tarr, P. I., Gordon, C. A. \& Chandler, W. L. (2005). Shiga toxinproducing Escherichia coli and haemolytic uremic syndrome. Lancet 365, 1073-1086.

Wieler, L. H., Tigges, M., Ebel, F., Schaferkordt, S., Djafari, S., Schlapp, T., Baljer, G. \& Chakraborty, T. (1996). The enterohemolysin phenotype of bovine Shiga-like toxin-producing Escherichia coli (SLTEC) is encoded by the EHEC-hemolysin gene. Vet Microbiol 52, 153-164.

World Health Organization (1987). Programme for control of diarrhoeal diseases. In Manual for Laboratory Investigation of Acute Enteric Infections (CDD/93.3, rev.1), pp. 9-20. Geneva: World Health Organization. 